UDK: 656.11.021

DOI: https://doi.org/10.24867/10DS10Vasiljevic

\title{
VREDNOVANJE PRIJEDLOGA RJEŠENJA ZA POBOLJŠANJE USLOVA ODVIJANJA SAOBRAĆAJA NA RASKRSNICI U BIJELJINI
}

\section{EVALUATION OF THE PROPOSED SOLUTIONS TO IMPROVE TRAFFIC CONDITIONS AT ROUNDABOUT IN BIJELJINA}

\author{
Mihajlo Vasiljević, Fakultet tehničkih nauka, Novi Sad
}

\begin{abstract}
Oblast - SAOBRAĆAJ I TRANSPORT
Kratak sadržaj - U okviru ovog rada potrebno je izvršiti kapacitivnu analizu raskrsnice. Utvrditi postojeće stanje, uraditi prognozu za 10 godina, dati prijedlog rješenja za poboljšanje uslova odvijanja saobraćaja, izvršiti funkcionalno, ekonomsko $i$ ekološko vrednovanje predloženih rješenja. Za svaku varijantu potrebno je izračunati troškove izgradnje, troškove goriva kao $i$ troškove zagađenja vazduha. Nakon toga potrebno je vrednovati sve varijante i predložiti najbolju.
\end{abstract}

Ključne reči: Kružna raskrsnica, kapacitet, nivo usluge, signalisana raskrsnica

\begin{abstract}
Within the paper, it is necessary to perform a capacitive analysis of the intersection. Determine the existing situation, make a forecast for 10 years, give a proposal for a solution to improve traffic conditions, perform a functional, economic and environmental evaluation of the proposed solutions. For each variant, it is necessary to calculate construction costs, fuel costs as well as air pollution costs. After that, it is necessary to evaluate all variants and suggest the best one.
\end{abstract}

Keywords: Roundabout, capacity, level of service, signalized intersection

\section{UVOD}

Tema ovog rada jeste da se vrednuje više varijanti raskrsnice i predloži najbolja. Pod vrednovanjem i upravljanjem projektima podrazumijeva se procedura ocjenjivanja i odlučivanja u sitemu optimalnog razvoja i korišćenja putne mreže.

U okviru rada izvršena je analiza kružne raskrsnice koja se nalazi u Bijeljini u Ulici Nikole Tesle - 27.marta Srpske vojske - Žrtava fašističkog terora i dat je prijedlog mjera za poboljšanje uslova odvijanja saobraćaja. Funkcionalnim, ekološkim i ekonomskim vrednovanjem predloženih rešenja dobijeno je optimalno rješenje koje je i predloženo za realizaciju.

\section{TEORIJSKE OSNOVE}

Raskrsnice, kao mjesta gdje dolazi do presijecanja saobraćajnih tokova, sa aspekta kapaciteta i nivoa usluga, predstavljaju potencijalno kritična mjesta na putnoj i uličnoj mreži.

\section{NAPOMENA:}

Ovaj rad proistekao je iz master rada čiji mentor je bio dr Nenad Ruškić, vanr. prof.
Jedan od čestih načina regulisanja saobraćaja na raskrsnicama zasniva se na izgradnji tkz. kružnih raskrsnica. Kružna raskrsnica jeste kanalisana kružna raskrsnica sa zatvorenim, djelimično prolaznim ili prolaznim središnjim saobraćajnim ostrvom i kružnim kolovozom koji veže tri ili više krakova preko kojih saobraćaj teče u suprotnom smjeru od kazaljke na satu. Izgled kružne raskrsnice prikazan je na slici 1 [1].

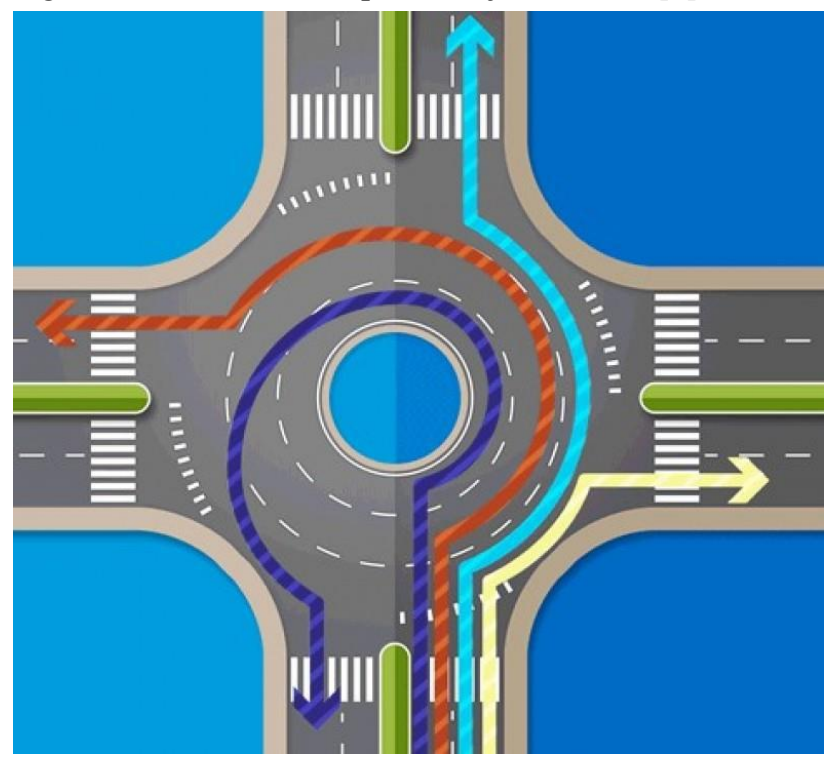

Slika 1. Ilustrovani prikaz kružne raskrsnice

\subsection{Kružne raskrsnice}

Projektovanje geometrije savremenih raskrsnica sa kružnim tokom predstavlja traženje kompromisa između apaciteta i sigurnosti. Raskrsnice sa kružnim tokom funkcionišu sigurnije ukoliko geometrijski element uslovljavaju smanjenje prilazne, odnosno, brzine $\mathrm{u}$ kružnom toku.

Nasuprot tome, ovakva geometrija uslovljava smanjenje kapaciteta raskrsnice. Takođe mnogi geometrijski elementi uslovljeni su manevarskim sposobnostima najvećeg vozila očekivanog na raskrsnici.

Osnovni oblik i karakteristike zavise i od položaja raskrsnice u mreži (gradska, vangradska), kao i od očekivanog prisustva pešaka odnosno biciklističkog saobraćaja. Takođe, različit pristup projektovanju se primenjuje kod raskrsnica sa jednom ili više traka $u$ kružnom toku [2].

Karakteristike kružnih raskrsnica po kojima se razlikuju od klasičnih površinskih raskrsnica, su sledeće: 
$>$ Kružne raskrsnice su raskrsnice sa kombinacijom isprekidanog i neisprekidanog saobraćajnog toka;

$>$ Vozila u kružnom toku imaju prednost pred vozilima iz ulivnih pravaca (u kružnim raskrsnicama ne važi pravilo ,desne strane“);

$>$ Vozilo na ulazu u kružnu raskrsnicu se u slučaju slobodnog kružnog kolovoza ne zaustavlja, već smanjenom brzinom ulazi u kružni tok;

$>$ Kružne raskrsnice, bez obzira na tip i način izvođenja, omogućavaju samo vožnju sa malim brzinama i velikim uglom skretanja prednjih točkova;

$>$ Za pešake i bicikliste u kružnim raskrsnicama važe ista pravila kao u klasičnim raskrsnicama;

$>$ U kružnim raskrsnicama je zabranjeno kretanje unazad;

$>$ Dugačkim vozilima je dozvoljeno da tokom vožnje po kružnom kolovozu koriste i neasfaltirani (kaldrmisani) deo kružnog kolovoza (pregazni deo centralnog ostrva), za mala vozila to nije potrebno [3].

Proces planiranja počinje sa određivanjem preliminarnog oblika i funkcionalnih karakteristika raskrsnice. Određuje se minimalni potrebni broj saobraćajnih traka na prilazima i na osnovu toga kategorija raskrsnice koja će u najvećoj mjeri zadovoljiti programske zahteve: mini ili normalna, sa jednom ili više saobraćajnih traka u kružnom toku, gradska ili vangradska itd. Sa razvojem procesa projektovanja neke polazne osnove mogu biti promijenjene [4]

Vrednovanje projektnog rješenja obično se vrši metodom dobit-troškovi (cost-benefit analiza). Dobit se razmatra $u$ pogledu bezbednosti (smanjenja broja nezgoda: nezgoda sa poginulim licima, sa poverđenim licima, materijalna šteta), funkcionalnosti (izraženo kroz vrem čekanja vozila-sati) i zaštite životne sredine (potrošnja goriva, emisija štetnih gasova, emisija buke). Troškovi se izražavaju kroz troškove građenja, eksploatacije i održavanja (osvetljenje, horizontalna i vertikalna signalizacija, uređenje prostora...) [5].

Obrazac za proračun vremenskih gubitaka na kružnoj raskrsnici dat je sledećim izrazom:

$d=\frac{3600}{c}+900 T\left[x-1+\sqrt{(x-1)^{2}+\frac{\left(\frac{3600}{c}\right) \cdot x}{450 T}}\right]+5 \times \min [x, 1]$

Gdje su:

T- vremenski interval za koji se posmatraju vremenski gubici;

$\mathrm{X}$ - predstavlja odnos protoka i kapaciteta $(V C)$.

\subsection{Signalisane raskrsnice}

U funkcionalnom smislu raskrsnica predstavlja najsloženiji element saobraćajne mreže. To je mesto gde se presecaju putanje saobraćajnih tokova različitog usmerenja, gde pojedini tokovi menjaju pravac, gde se odvija niz manevara, mesto gde se najčešće realizuju presecanja pešačkih i tokova vozila. U tom smislu, raskrsnica predstavlja prostor povećane koncentracije konflikata i povećanog rizika od nastajanja nezgoda.
Svjetlosni signali vrše vremensku raspodjelu prava korišćenja površine raskrsnice na konfliktne saobraćajne tokove u skladu sa izabranim kriterijumom upravljanja. Svjetlosni signali predstavljaju najviši hijerarhijski nivo regulisanja na raskrsnici.

Osnovne prednosti svetlosnih signala u odnosu na ostale nivoe upravljanja su jednoznačnost upravljačke informacije, fleksibilnost u radu, jednostavna promena upravljanja, mogućnost rada zavisnog od niza odabranih činilaca saobraćaja i okruženja, neprekidnost rada, i sl.

Osnovni elementi signalnog plana na signalisanoj raskrsnici su:
$>$ Ciklus
$>$ Zeleno vrijeme;
$>$ Međufazno vrijeme;
$>$ Faza.

Prosječni vremenski gubici po vozilu za datu grupu traka iste namjene računaju se na sledeći način:

$$
d=d_{1}(P F)+d_{2}+d_{3}
$$

gdje je:

d - ukupni vremenski gubici (s/voz);

$\mathrm{PF}$ - faktor progresije (PF $=1$, ako je dolazak vozila slučajnog karaktera);

d1 - uniformni vremenski gubici;

d2 - dodatni vremenski gubici usljed slučajnog dolaska vozila na raskrsnicu;

d3 - gubici usljed reda čekanja.

Uniformni vremenski gubici (d1) se računaju na sledeći način:

$$
d_{1}=\frac{0,5 C\left(1-\frac{g}{C}\right)^{2}}{1-\left[\min (1, X) \frac{g}{C}\right]}
$$

gdje je:

g -efektivno zeleno vrijeme za grupu traka;

C - dužina trajanje ciklusa na posmatranoj raskrsnici;

$\mathrm{x}=\mathrm{q} /$ Cik - odnos toka i kapaciteta, odnosno, stepen zasićenja za grupu traka.

Dodatni vremenski gubici usljed slučajnog dolaska vozila na raskrsnicu računaju se na sledeći način:

$$
d_{2}=900 T\left[(X-1)+\sqrt{(X-1)^{2}+\frac{8 k l X}{c T}}\right]
$$

gdje je:

$\mathrm{T}$ - trajanje analiziranog perioda;

$\mathrm{k}$ - faktor koji zavisi od rada komandnog uređaja $(\mathrm{k}=0.5$ za signale sa fiksnim planom);

1 - uzvodna filtracija/mjerenje korekcionog faktora; $\mathrm{x}=\mathrm{q} / \mathrm{Cik}-$ odnos toka i kapaciteta;

C - dužina trajanje ciklusa.

Gubici usljed reda čekanja, računaju se na sledeći način:

$$
d_{3}=\frac{1800 Q_{h}(1+u) t}{C T}
$$

gdje je:

Qh - veličina prethodnog reda na početku perioda T; 
u -parametar kašnjenja;

$\mathrm{T}$ - trajanje analiziranog perioda $(\mathrm{h})$;

$\mathrm{t}$ - kapacitet grupe traka i (voz/h).

\section{POSTOJEĆE STANJE RASKRSNICE}

Analizirana kružna raskrsnica nalazi se na području grada Bijeljine, locirana je u centralnoj gradskoj zoni i mjesto je ukrštanja ulica: Nikole Tesle, 27. marta, Srpske vojske i Žrtava fašističkog terora. Na slici 8. prikazan je položaj raskrsnice $u$ odnosu na centralno područje grada. Raskrsnica je od centra grada udaljena svega $550 \mathrm{~m}$. Na osnovu ovog podatka ali i blizine ostalih značajnijih lokacija gdje je povećana koncentracija ljudi (gradski park, bolnica, autobuska stanica, pijaca, tržni centar i dr.) na posmatranoj raskrsnici primjećene su česte gužve i zastoji, pri čemu se stvaraju redovi čekanja.

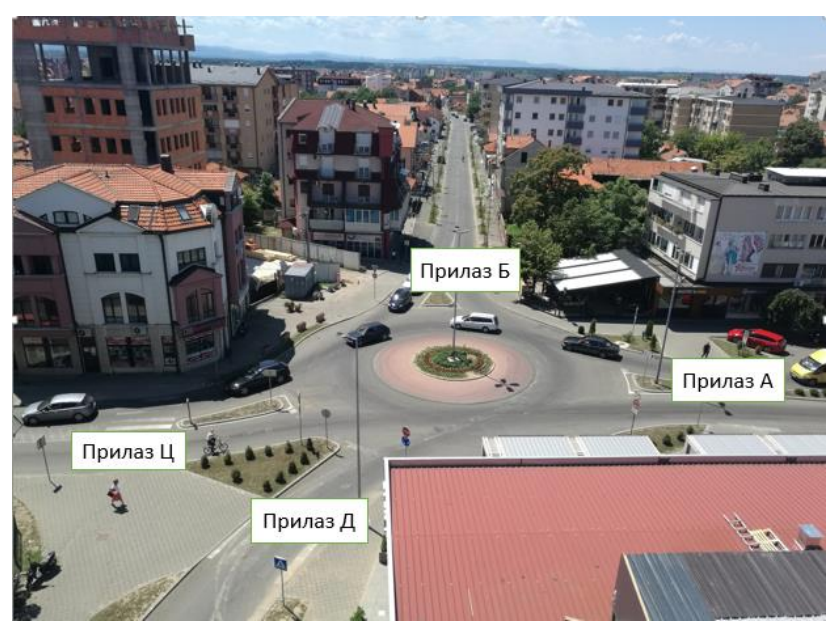

Slika 2. Prikaz prilaza na raskrsnici

Podaci dobijeni brojanjem, prikazani grafički. Časovna distribucija protoka na raskrnici prikazana je na slici 3. Na istoj slici je prikazan vršni sat kada je najveći protok, a to je od 14:00 do 15:00.

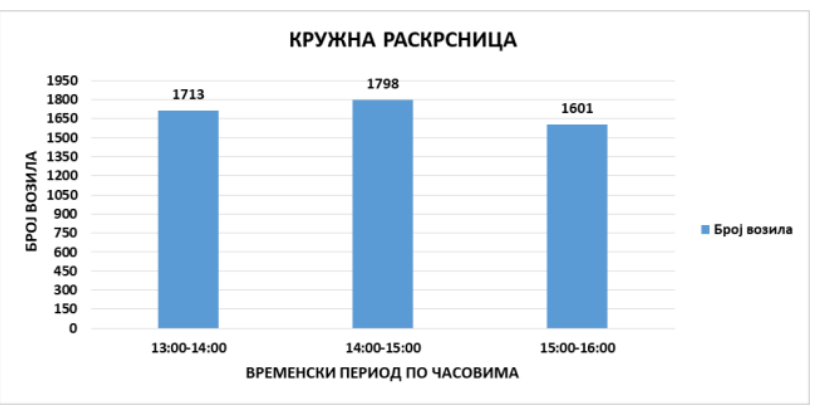

Slika 3. Grafički prikaz časovne distribucije protoka

$\mathrm{Na}$ slici 4. dat je grafički prikaz procentualnog odnosa strukture toka u odnosu na cijelu raskrsnicu.

\section{PROGNOZA SAOBRAĆAJNOG OPTEREĆENJA I PRIJEDLOG RJEŠENJA}

Razvoj oblasti vezane za prognozu saobraćaja desio se u okolnostima kada je porast saobraćaja izazvan brzim razvojem i masovnom upotrebom putničkih automobila, prije svega $u$ gradovima, počeo da stvara brojne probleme, pa se pojavila potreba za složenijim oblicima praćenja, analize i kontrole razvoja saobraćaja. Polovinom prošlog veka došlo je do intenzivnog razvoja računarske tehnologije i njene primene u prognozi saobraćaja.

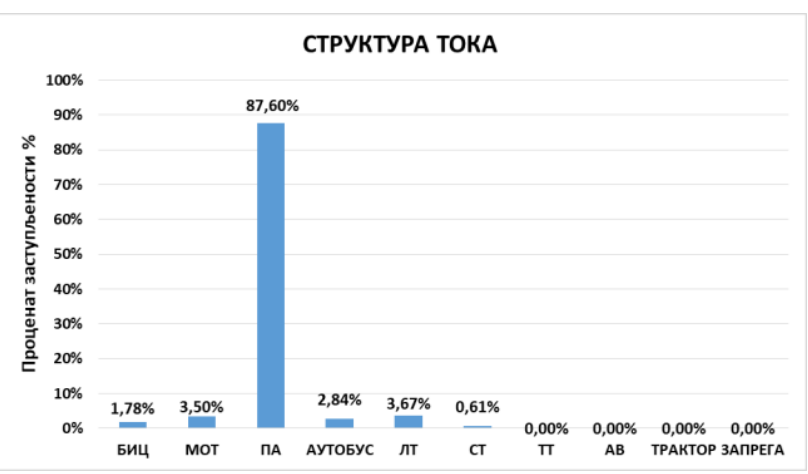

Slika 4. Procentualni odnos strukture toka kružne raskrsnice za period vršnog sata

Prognoza saobraćaja je veoma važna prilikom odabira buduće varijante nekog projekta. Ukoliko se predviđanje saobraćaja ne obavi na pravi način izgrađeni saobraćajni objekat neće moći da zadovolji potrebe za zahtevanim kapacitetom ili će biti predimenzionisan. Usled ovoga javlja se veliki problem koji se mora opet rješavati i njegovi troškovi proširenja ili ponovne izgradnje mogu da koštaju više nego što je stajala sama izgradnja prvobitnog objekta. Kod predimenzionisane prognoze saobraćaja objekti ostaju neiskorišćeni i ekonomski njihova izgradnja nije opravdana.

$\mathrm{Na}$ narednoj slici je dat prikaz prognoziranog saobraćajnog opterećenja za naredni 10-godišnji period, u vršnom vremenskom periodu, od 14:00-15:00 časova, po realističnoj varijanti.



Slika 5. Prognoza saobraćajnog opterećenja u vršnom periodu

U vršnom periodu od 14:00-15:00 časova, u baznoj 2019. godini, izbrojano je 1798 vozila, dok se nakon 10 godina, po realističkoj varijanti predviđa da će se taj broj povećati na 2561 vozila u istom času.

Razvoj i testiranje varijantnih rešenja predstavlja jednu od ključnih faza u ovom radu. Cilj ovog rada je da se na osnovu postojećih geometrijskih ograničenja predlože i analiziraju varijante, kako bi se našlo optimalno rešenje za datu raskrsnicu.

Analizom rezultata kapaciteta i nivoa usluge za posmatranu raskrsnicu utvrđeno je da sadašnja organizacija i odvijanje saobraćaja ne mogu da zadovolje nesmetano kretanje saobraćaja. Potrebno je izvesti najbolju i najoptimalniju varijantu kako bi se prevazišao problem i poboljšao nivo usluge na svim prilazima na raskrsnici. Predložene varijante su: 
$>$ Varijanta 0- Kružna raskrsnica-zadržava se postojeća geometrija raskrsnice;

$>$ Varijanta 1- Kružna raskrsnica sa"bypass" trakama na svim prilazima i jednom trakom $u$ kruženju;

> Varijanta 2- Kružna raskrsnica sa "bypass" trakama na svim prilazima i dvije trake $u$ kruženju;

$>$ Varijanta 3- Četvorokraka signalisana raskrsnica. $\mathrm{Na}$ osnovu predloženih varijanti odlučivaće se koja je varijanta najpovoljnija za posmatranu raskrsnicu, ali treba voditi računa da izabrana varijanta pruža bolje uslove odvijanja saobraćaja, da smanji ili eliminiše zastoje i formiranje redova, da se smanje vremenski gubici i da se poboljša nivo usluge na cijeloj raskrsnici.

$\mathrm{Na}$ osnovu prethodno prikazanih podataka, za potrebe funkcionalnog vrednovanja, data je uporedna analiza dobijenih vrednosti. Dobijeni podaci su dati sledećom tabelom. (Var-varijanta)

Tabela 1. Prikaz vremenskih gubitaka i nivo usluge na raskrsnici

\begin{tabular}{|c|c|c|c|c|c|}
\hline $\begin{array}{c}\text { Nivo } \\
\text { usluge }\end{array}$ & Prilaz 1 & Prilaz 2 & Prilaz 3 & Prilaz 4 & Raskrsnica \\
\hline Var 0 & $\begin{array}{c}224,32 \\
(\mathrm{~F})\end{array}$ & $\begin{array}{c}275,25 \\
(\mathrm{~F})\end{array}$ & $\begin{array}{c}139,70 \\
(\mathrm{~F})\end{array}$ & $\begin{array}{c}471,12 \\
(\mathrm{~F})\end{array}$ & $\begin{array}{c}255,80 \\
(\mathrm{~F})\end{array}$ \\
\hline Var 1 & $\begin{array}{c}105,64 \\
(\mathrm{~F})\end{array}$ & $\begin{array}{c}33,42 \\
(\mathrm{D})\end{array}$ & $\begin{array}{c}139,70 \\
(\mathrm{~F})\end{array}$ & $\begin{array}{c}84,65 \\
(\mathrm{~F})\end{array}$ & $\begin{array}{c}95,44 \\
(\mathrm{~F})\end{array}$ \\
\hline Var 2 & $\begin{array}{c}61.41 \\
(\mathrm{~F})\end{array}$ & $\begin{array}{c}25,70 \\
(\mathrm{D})\end{array}$ & $\begin{array}{c}84,22 \\
(\mathrm{~F})\end{array}$ & $\begin{array}{c}59,10 \\
(\mathrm{~F})\end{array}$ & $\begin{array}{c}61,20 \\
(\mathrm{~F})\end{array}$ \\
\hline Var 3 & $\begin{array}{c}28,60 \\
(\mathrm{C})\end{array}$ & $\begin{array}{c}48,60 \\
(\mathrm{D})\end{array}$ & $\begin{array}{c}36,00 \\
(\mathrm{D})\end{array}$ & $\begin{array}{c}30,90 \\
(\mathrm{C})\end{array}$ & $\begin{array}{c}35,00 \\
(\mathrm{C})\end{array}$ \\
\hline
\end{tabular}

$\mathrm{Na}$ osnovu podataka iz prethodne tabele može se zaključiti da je kod varijante 3 zabeležen najpovoljniji nivo usluge $\mathrm{C}$, koji je praćen smanjenjem vremenskih gubitaka koji iznose $35 \mathrm{~s} / \mathrm{voz}$ na nivou cijele raskrnice. Kada je riječ o troškovima gradnje oni su sledeći:

$>$ Varijanta 0- 0€;

$>$ Varijanta 1-15000€;

$>$ Varijanta 2- $25000 €$

$>$ Varijanta 3-70 000€;

Pored troškova izgradnje, računati su još i troškovi goriva pri zaustavljanju i troškovi zagadjenja vazduha.

Nakon toga ostaje još da se izračunaju ukupni troškovi koji predstavljaju zbir svih ovih troškova i samim tim da se predloži optimalno rješenje.

Tabela 2. Ukupni troškovi po varijantama

\begin{tabular}{|c|c|c|c|c|}
\hline & $\begin{array}{c}\text { Troškovi } \\
\text { goriva }\end{array}$ & $\begin{array}{c}\text { Troškovi } \\
\text { izgradnje }\end{array}$ & $\begin{array}{c}\text { Troškovi } \\
\text { zagađenja }\end{array}$ & $\begin{array}{c}\text { Ukupni } \\
\text { troškovi } \\
(€)\end{array}$ \\
\hline Var 0 & 3376311 & 0 & 16442 & 3392753 \\
\hline Var 1 & 1322309 & 15000 & 6439 & 1343748 \\
\hline Var 2 & 854322 & 25000 & 4160 & 883482 \\
\hline Var 3 & 666732 & 70000 & 3246 & 739978 \\
\hline
\end{tabular}

Na osnovu tabele ukupnih troškova, zaključuje se da varijanta 0 predstavlja najnepovoljniji slučaj sa 3.392.753,00 € troškova. Varijanta 1 je varijanta u kojoj su izvedeni građevinski radovi vezani za izgradnju "bypass" traka radi poboljšanja uslova odvijanja saobraćaja, što je rezultovalo smanjenjem ukupnih troškova koji iznose 1.343.748,53€. Kod varijante 2 je uz značajne građevinske intervencije koje podrazumijevaju pored "bypass" traka i izgradnju još jedne trake u kruženju, došlo do smanjenja ukupnih troškova koji iznose $883.482,47 €$. Varijanta 3 koja podrazumijeva izgradnju signalisane raskrsnice se izdvojila kao varijanta sa najnižim ukupnim troškovima koji iznose oko 740.000,00 € u 10-godišnjem periodu.

\section{ZAKLJUČAK}

Različita rješenja problema u saobraćaju dovode do izbora optimalnog rješenja i samim ti do poboljšanja uslova odvijanja saobraćaja. Nakon obavljene analize postojećeg stanja predložena su 3 moguća rješenja u odnosu na postojeće stanje koje se nije pokazalo kao dobro. Pored uslova odvijanja saobraćaja utvrđeni su i troškovi gradnje s ciljem da se pronađe rješenje koje bi bilo izvodljivo i u skladu sa ekonomskim mogućnostima. Da bi se na najbolji mogući način opisali troškovi $u$ pojedinim varijantama urađena je analiza potrošnje goriva i zagađenja vazduha da bi se vremenski gubici mogli iskazati novčano.

$\mathrm{Na}$ osnovu dobijenih rezultata funkcionalnog, ekološkog i ekonomskog vrednovanja predloženih rješenja, može se zaključiti da je optimalno i najracionalnije usvojiti Varijantu 3. tj, da se umjesto kružne raskrsnice izgradi četvorokraka signalisana raskrsnica.

\section{LITERATURA}

[1] http://ltablice.com

[2] Kenjić, Z. Izbor tipa raskrsnice primjenom multikriterijske analize, 1-9.

[3] Mitić D, Vukanović S, kružne raskrsnice, Saobraćajni fakultet 1990

[4] Pravilnik o saobraćajnoj signalizaciji, 2010. Pravilnik je objavljen u "Službenom glasniku RS", broj 26/2010.,

[5] Smjernice projektovanje, građenje održavanje i nadzor na putevima. Knjiga I, 2005. Bosna i Hercegovina.

\section{Kratka biografija:}

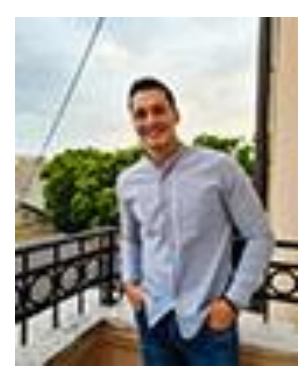

Mihajlo Vasiljević rođen je u Bijeljini 1996. godine. Diplomski rad na Fakultetu tehničkih nauka iz oblasti Saobraćaj i transport odbranio je 2019. godine. Iste godine upisao je master akademske studije. 